\title{
Transition region of TEC enhancement phenomena during geomagnetically disturbed periods at mid-latitudes
}

\author{
K. Unnikrishnan ${ }^{1,2}$, A. Saito ${ }^{3}$, Y. Otsuka ${ }^{4}$, M. Yamamoto ${ }^{1}$, and S. Fukao ${ }^{1}$ \\ ${ }^{1}$ Research Institute for Sustainable Humanosphere, Kyoto University, Uji, Kyoto 611 0011, Japan \\ ${ }^{2}$ also at: Department of Physics, N S S Hindu College, Changanacherry, Kerala 686 102, India \\ ${ }^{3}$ Department of Geophysics, Graduate School of Science, Kyoto University, Kyoto 606-8502, Japan \\ ${ }^{4}$ Solar-Terrestrial Environment Laboratory, Nagoya University, Toyokawa, Japan
}

Received: 27 March 2005 - Revised: 30 September 2005 - Accepted: 11 October 2005 - Published: 21 December 2005

\begin{abstract}
Large-scale TEC perturbations/enhancements observed during the day sectors of major storm periods, 12 13 February 2000, 23 September 1999, 29 October 2003, and 21 November 2003, were studied using a high resolution GPS network over Japan. TEC enhancements described in the present study have large magnitudes $\left(\geq 25 \times 10^{16}\right.$ electrons $/ \mathrm{m}^{2}$ ) compared to the quiet-time values and long periods ( $\geq 120 \mathrm{~min}$ ). The sequential manner of development and the propagation of these perturbations show that they are initiated at the northern region and propagate towards the southern region of Japan, with velocities $>350 \mathrm{~m} / \mathrm{s}$. On 12 February 2000, remarkably high values of TEC and background content are observed at the southern region, compared to the north, because of the poleward expansion of the equatorial anomaly crest, which is characterized by strong latitudinal gradients near $35^{\circ} \mathrm{N}\left(26^{\circ} \mathrm{N}\right.$ geomagnetically). When the TEC enhancements, initiating at the north, propagate through the region $39-34^{\circ} \mathrm{N}\left(30-25^{\circ} \mathrm{N}\right.$ geomagnetically), they undergo transitions characterized by a severe decrease in amplitude of TEC enhancements. This may be due to their interaction with the higher background content of the expanded anomaly crest. However, at the low-latitude region, below $34^{\circ} \mathrm{N}$, an increase in TEC is manifested as an enhanced ionization pattern (EIP). This could be due to the prompt penetration of the eastward electric field, which is evident from high values of the southward Interplanetary Magnetic Field component (IMF $B_{z}$ ) and AE index. The TEC perturbations observed on the other storm days also exhibit similar transitions, characterized by a decreasing magnitude of the perturbation component, at the region around $39-34^{\circ} \mathrm{N}$. In addition to this, on the other storm days, at the low-latitude region, below $34^{\circ} \mathrm{N}$, an increase in TEC (EIP feature) also indicates the repeatability of the above scenario. It is found that, the latitude and time at which the decrease in
\end{abstract}

Correspondence to: K. Unnikrishnan

(kaleekkalunni@yahoo.com) magnitude of the perturbation component/amplitude of the TEC enhancement are matching with the latitude and time of the appearance of the high background content. In the present study, on 12 February 2000, the F-layer height increases at Wakkanai and Kokubunji, by exhibiting a typical dispersion feature of LSTID, or passage of an equatorward surge, which is matching with the time of occurrence of the propagating TEC perturbation component. Similarly, on 29 October 2003, the increase in F-layer heights by more than $150 \mathrm{~km}$ at Wakkanai and $90 \mathrm{~km}$ at Kokubunji around 18:00 JST, indicates the role of the equatorward neutral wind. On that day, TEC perturbation observed at the northern region, after 18:30 JST, which propagates towards south, could be caused mainly by the equatorward neutral wind, leading to an F-layer height increase. These observations imply the role of the equatorward neutral wind, which increases the Flayer height, by lifting the ionization to the regions of lower loss during daytime, when production is still taking place, which, in turn, increases the TEC values.

Large-scale traveling ionospheric disturbances (LSTIDs) are considered as ionospheric manifestations of the passage of Atmospheric Gravity Waves (AGWs) that are generated at the high latitude by energy input from the magnetosphere to the low-latitude ionosphere. This study shows that largescale TEC perturbations observed here are produced at the northern region due to the combined effects of the equatorward neutral wind, the subsequent F-layer height increase, and LSTIDs. When these perturbation components propagate through the region, $39-34^{\circ} \mathrm{N}$, they undergo transitions characterised by a decrease in magnitude. Also, at the lowlatitude region, below $34^{\circ} \mathrm{N}$, an increase in the TEC exhibits EIP feature, due to the prompt penetration of the eastward electric field.

Keywords. Ionosphere (Ionospheric disturbances) - Magnetospheric physics (Storms and substorms) 


\section{Introduction}

In the last decade, several new features, like turbulent upwelling, electrodynamics of spread $\mathrm{F}$, airglow observations of mesoscale low-velocity traveling ionospheric disturbances (TIDs), damping of LSTIDs, etc., of the mid-latitude ionosphere have been discovered by observations of radars, satellites, all-sky imagers and GPS receivers (Fukao et al., 1991; Miller et al., 1997; Garcia et al., 2000). The worldwide distribution of the GPS receivers of the International GPS Service (IGS) network makes it possible to draw a global TEC map every 15 min (Wilson, 1995; Ho et al., 1996). Ho et al. (1996) studied the global distribution of TEC variations during a magnetically disturbed period with more than 60 worldwide GPS receivers. TEC variations in a local area have also been studied with GPS receivers in equatorial (Kelley et al., 1996; Musman et al., 1997), mid-latitude (Beach et al., 1997), and high-latitude (Aarons, 1997) regions. It is known that TIDs are the ionospheric manifestations of the passage of Atmospheric Gravity Waves (AGWs) that are generated at the high latitude by energy input from magnetosphere to the low-latitude ionosphere. Saito et al. (1998; 2001; 2002) have conducted studies on nighttime TIDs propagating through the Japanese mid-latitude sector with velocities up to $150 \mathrm{~m} / \mathrm{s}$, which produce a magnitude of perturbation structures (with respect to the background content) up to 1 TECU $\left(1\right.$ TECU $=10^{16}$ electrons $\left./ \mathrm{m}^{2}\right)$.

During major geomagnetic storms, the mid-latitude region is a scene for the influence of low-latitude and high-latitude regimes and the conflict between the mechanisms, which are active in those regions. Hence, the storm-time TEC variations at the region $15-35^{\circ}$ geomagnetic latitudes are extremely complex. The storm-associated disturbance electric field, which is active at equatorial/low latitudes, the associated poleward expansion of equatorial ionization anomaly (EIA), and the storm-driven disturbance neutral wind system originating at the high-latitude regime, will produce unpredictable TEC perturbations over the mid-latitude region. TEC perturbations propagating through this region suffer severe damping and undergo interesting transitions due to the ionization gradients of the expanded anomaly crest.

Many excellent studies and reviews to summarize our current understanding of ionospheric storms have been published during the last few years (Fuller-Rowell et al., 1994; Abdu, 1997; Prölss, 1997; Buonsanto, 1999). It is known that two mechanisms are attributed to the positive storm-time response of the ionosphere. One is the increase in the F-layer height due to the equatorward blowing meridional winds which drag the ionization upward along the magnetic field lines, where the recombination rate is lower (Prölss, 1995; Kutiev and Muhtarov, 2003). The other is downwelling of the molecule rich gas $\left(\mathrm{N}_{2}\right.$ and $\left.\mathrm{O}_{2}\right)$ from F-layer heights (FullerRowell et al., 1996; Field and Rishbeth, 1997). This mechanism assures a decreased recombination at F-layer heights that yields an increase of ionization.

The physical mechanism, which is traditionally involved in order to explain the diurnal variation of the equatorial anomaly, is the so-called fountain effect and this fountain is controlled by the $\boldsymbol{E} \times \boldsymbol{B}$ drift. In a review regarding the response of major phenomena of the equatorial ionosphere thermosphere system to magnetospheric disturbances, Abdu (1997) described the expansion of the equatorial ionization anomaly (EIA) in latitude during intense storms. Observations from the far eastern sector during storm conditions showing a poleward expansion of the equatorial anomaly zone attributed to an enhanced eastward electric field at the equator, have been presented by Tanaka (1981), Forbes (1989) and Huang and Cheng (1993). By generating ionospheric tomographic images for a chain of six stations from $14.6^{\circ} \mathrm{N}$ to $31.3^{\circ} \mathrm{N},\left(3.3^{\circ} \mathrm{N}\right.$ to $19.7^{\circ} \mathrm{N}$ geomagnetically), Yeh et al. (2001) have observed that, on an average day, the crest forms at 09:00 LT and moves poleward up to $21.7^{\circ} \mathrm{N}$ (geographically) and after that its density decreases. These prior works revealed the expansion of the equatorial anomaly crest poleward up to $20^{\circ}$ dip latitude only.

During the first day of a storm, a large increase in the F-region electron density and the TEC are observed in the afternoon and evening hours at mid-latitude (Mendillo et al., 1972; Foster, 1993; Buonsanto, 1995), which may be known as the dusk effect. In the American sector, this phenomenon was studied by Buonsanto (1995), using incoherent scatter radar data collected at Millstone Hill and total electron content data from the north-south chain of stations during 26-27 May 1990, and he estimated the gradients in the electron density and in the velocity components. He suggested that a combination of mechanisms appear to have involved, including a TID, advection of high-density plasma from lower latitudes, and neutral composition changes. In another study at the same location, Foster (1993) observed that solar-produced F-region plasma can be transported by the enhanced convection electric fields, through the noon time cleft, from middle and low latitudes, and this stormenhanced plasma density feature produces positive enhancements during the dusk sectors of the mid latitude, at the early stages of storm.

The energy and particle injection that takes place during magnetospheric disturbances produces multiple changes to the Earth's high-latitude ionosphere-thermosphere system (Pincheira et al., 2002). Prompt penetration (PP) magnetospheric electric fields have been observed during times of sudden changes in high-latitude convection, as evident in the ionospheric response features observed at low and equatorial latitudes (Fejer and Scherliess, 1998; Abdu et al., 1995; Sobral et al., 1997). These electric fields have also been observed at mid latitudes (Blanc, 1983). Recently, Huang et al. (2002) presented observations of mid-latitude ionospheric plasma perturbations during two events and the direct relationship between the oscillations of the interplanetary/solar wind pressure and the mid-latitude dayside ionosphere. Their study suggested that the mid-latitude ionospheric electron density perturbations ( $\sim 30 \%$ within $30-70 \mathrm{~min}$ ) were caused by the penetration of magnetospheric electric fields, which were controlled or modulated by the oscillations in the $\mathrm{IMF} /$ solar wind pressure. The magnetospheric electric fields 
penetrate to the mid-latitude ionosphere and cause an up and down motion of the ionospheric plasma. The plasma density is increased or decreased due to the variations in the recombination rate at different altitudes.

Basu et al. (2001) have studied the ionospheric effects of major magnetic storms during September and October 1999, by using multi-instrumental techniques at mid- and equatorial latitudes. They found that, at mid-latitude, the PP electric field is the cause for the TEC increase, followed by a rapid TEC decrease related to the equatorward motion of the midlatitude trough. By analyzing the GPS data and Digisonde data from Westford, Massachusetts $\left(42.6^{\circ} \mathrm{N}, 288.5^{\circ} \mathrm{E}\right)$, they observed evidence for an abrupt F-region height rise and an increase in the TEC ( $\sim 10$ TECU around 21:30 UT), during the storm period, which may be due to a combined effect of an eastward electric field in the presence of sunlight and advection of plasma from the lower latitude (Foster, 1993; Basu et al., 2001). Also, it is known that large-scale nighttime TEC enhancements during storms (Balan et al., 1991; Unnikrishnan et al., 2002) are different from those of largescale daytime TEC enhancements, due to the difference in the causative mechanisms.

Tsugawa et al. (2003) investigated the spatial structure and temporal evolution of LSTIDs and obtained their damping rates by considering the storm on 22 September 1999. Their studies show that the perturbation component and period of LSTIDs have maximum values up to 0.3 TECU and $90 \mathrm{~min}$, respectively. It may be noted that the TEC enhancements described in the present study are different from the previous studies based on LSTIDs, because of the much higher perturbation component ( $\geq 7$ TECU), period ( $\geq 120 \mathrm{~min}$ ) and magnitude ( $\geq 25$ TECU) of the TEC enhancements observed in the present study, compared to those of the LSTIDs.

In the present study, we observed storm-associated large TEC enhancements during the daytime, especially during the afternoon and evening hours (dusk sectors) over Japan by using GPS data. When these TEC enhancements propagate southward, around $36^{\circ} \mathrm{N}\left(27^{\circ} \mathrm{N}\right.$ geomagnetically), they undergo interesting transitions characterized by a severe decrease in the perturbation component and amplitude, due to the oppositions offered by the high background content at the southern region, due to the expanded anomaly crest. At the low-latitude region, below $34^{\circ} \mathrm{N}\left(25^{\circ} \mathrm{N}\right.$ geomagnetically), TEC enhancements are observed, manifesting as an enhanced ionization pattern (EIP) due to the prompt penetration (PP) eastward electric field associated with the magnetospheric convections during the storm. The role of the F-layer height variation during storms, observed using ionosonde data, was checked. We also observed that the boundary of the anomaly crest could be enhanced poleward, so as to bring high background content at the southern regions of the Japanese mid-latitude, during severe storms.

\section{Observations and method of analysis}

We have studied TEC perturbations during the day sectors, associated with four major geomagnetic storms. A major geomagnetic storm occurred during 11-12 February 2000, with storm sudden commencements (SSCs) at 02:58 and 23:53 UT on 11 February, and the main phase developed on 12 February with $D_{s t}$ min of $-133 \mathrm{nT}$ at 11:00 UT. TEC perturbations are observed during 02:00-06:00 UT on 12 February and during 05:30-08:00 UT on 13 February. The second major storm of this study occurred on 22 September 1999 , with SSC at 20:00 UT, with a $D_{s t}$ min of $-173 \mathrm{nT}$ at 22:00 UT and strong TEC perturbations were exhibited on 23 September during 06:00-08:30 UT. The third major storm we have studied occurred on 29 October 2003, with SSC at 06:00 UT. On 30 October, another SSC occurred at 17:00 UT. Two $D_{s t}$ minima were observed with values of $363 \mathrm{nT}$ and $-401 \mathrm{nT}$ at 00:00 UT and 22:00 UT, respectively, on 30 October. In association with this, TEC perturbations were observed on 29 October 2003 during 09:30-11:30 UT. The fourth major storm occurred on 20 November 2003 with SSC at 06:00 UT, with a $D_{s t}$ min of $-472 \mathrm{nT}$ at 19:00 UT. TEC perturbations were observed on 21 November during 06:30-08:30 UT.

From GEONET, the GPS network in Japan, TEC data can be derived from more than 1000 GPS receivers for a geographic latitude range $24-48^{\circ} \mathrm{N}$ and for a geographic longitude range $124-148^{\circ} \mathrm{E}$, every $30 \mathrm{~s}$. Two frequency observations (1575.42 and $1227.60 \mathrm{MHz}$ ) of the Global Positioning System (GPS) provide the relative ionospheric delay of electromagnetic waves traveling through the dispersive medium, and the total amounts of free electrons along the ray paths can be derived from these ionospheric delays (Saito et al., 1998). One receiver simultaneously receives signals from approximately 6 satellites. Therefore, TEC values are measured and recorded along more than 5000 satellite-receiver paths, every $30 \mathrm{~s}$ over Japan. This dense distribution of GPS receivers is suitable to study spatial structures and the temporal evolution of TEC perturbations in detail. The high resolution TEC maps over Japan have been derived with GEONET data since 1997 (Saito et al., 1998, 2001, 2002).

Otsuka et al. (2002) developed a new technique to derive the absolute values of vertical TEC, in which a weighted least-squares fitting is used to determine unknown instrumental biases, assuming that the hourly TEC average is uniform within an area covered by a GPS receiver. This technique used in previous studies (Tsugawa et al., 2003, 2004) can produce absolute values of TEC in the accuracy of $3 \times 10^{16}$ electrons $/ \mathrm{m}^{2}$.

In the present study, we used absolute values of vertical TEC by adopting single-station, slant-to-vertical TEC conversions. TEC data were averaged along the longitude range, since we are interested in the latitudinal variation of these perturbations over Japan. An additional precaution was taken to avoid possible errors during the conversion of slant to vertical TEC, due to high horizontal gradients. To minimize these errors, and those caused by the cycle slips, only those 


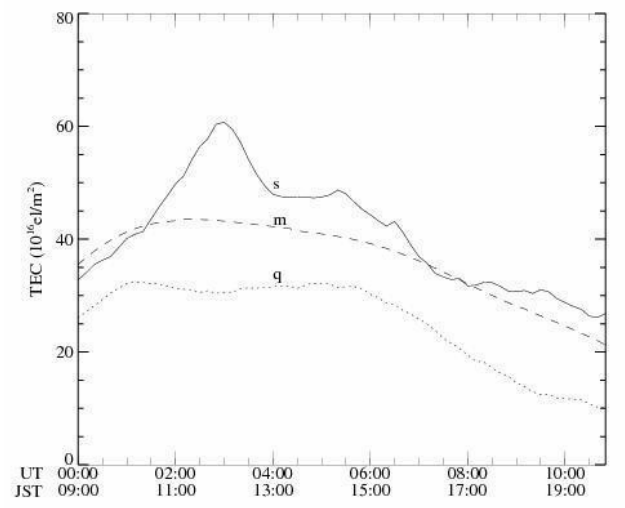

(a)

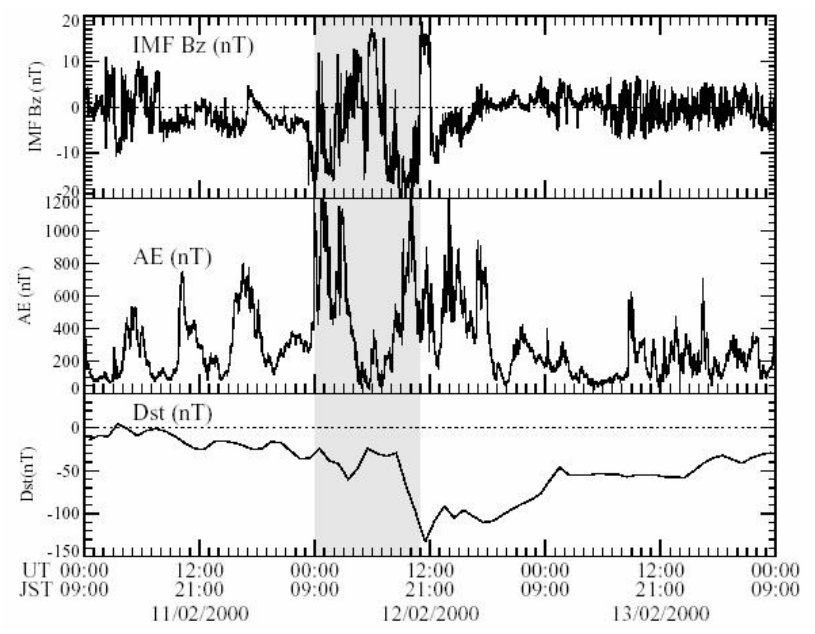

(b)

Fig. 1. (a) The comparison of typical temporal variations of storm-time (with a marking "s") and quiet-time reference (with a marking "q") TEC at $39^{\circ} \mathrm{N}$ (which is the longitudinal average along Japanese sector) with the IRI model values (with a marking "m") and (b) temporal variations of Interplanetary Magnetic Field component (IMF $B_{z}$ ), $A E$ index, and $D_{s t}$ during the period 11-13 February 2000. The shaded area in Fig. 1b corresponds to the duration considered for Fig. 1a.

data with an elevation angle above $55 \mathrm{deg}$ are considered for this study. At low- and high-latitude regions of the available range, the errors due to the estimation of the instrumental biases are larger and hence, we have chosen the best quality data over $32-44^{\circ} \mathrm{N}$. By using these precautions, absolute TEC can be derived with an accuracy of 2 TECU during storm and quiet times. Also, we found that the possible error factor in the absolute TEC at the boundary of the expanded anomaly region and the southward traveling perturbed component, due to the strong horizontal gradients in TEC, are limited to 1.8 and 1.5 TECUs, respectively, which will not affect the observations of the present study. By using the ionosonde data at Kokubunji $\left(35.7^{\circ} \mathrm{N}, 139.5^{\circ} \mathrm{E}\right)$ and Wakkanai $\left(45.4^{\circ} \mathrm{N}, 141.7^{\circ} \mathrm{E}\right)$, F-layer height and $f \circ \mathrm{F} 2$ variations during perturbations on 12 February 2000 and 29 October 2003 were compared with those of quiet-time values.

\section{Results}

Figure 1a shows the comparison of typical temporal variations of storm-time (with a marking "s") and quiet-time TEC (with a marking "q") at $39^{\circ} \mathrm{N}$ (which is the longitudinal average along the Japanese sector) with the IRI model values (with a marking " $\mathrm{m}$ "). As the reference, the average TEC was found of six quiet days with low $A_{p}$ and $D_{s t}$ values, prior to the storm day. On 12 February 2000, around 02:00 UT (11:00 JST), distinguishable storm associated TEC perturbations were initiated, where both quiet-time (reference) and IRI model values exhibited the usual diurnal trend. The shaded area in Fig. 1b corresponds to the duration considered for Fig. 1a. The temporal variations of the Interplanetary Magnetic Field component (IMF $B_{z}$ ), $A E$ index, and $D_{s t}$ during 11-13 February 2000 (Fig. 1b), show that these perturbations occurred during the initial and main phases of the geomagnetic storm. When the IMF $B_{z}$ is northward, its sign will be positive and when it becomes southward, its sign will change to negative. It is seen that IMF $B_{z}$ becomes predominantly southward and attains a maximum value of $-18 \mathrm{nT}$ around 23:00 UT on 11 February 2000 (08:00 JST, on 12 February 2000) and continues the same trend for a few hours with large oscillations. Due to the influence of the southward IMF $B_{z}$, the $A E$ index shows a maximum value of about 1200 nT around 00:00 UT (09:00 JST) on 12 February 2000 and it continues to be higher for the next few hours with small oscillations. After changing the direction towards the north, IMF $B_{z}$ again becomes southward after 06:00 UT (15:00 JST on 12 February 2000). Subsequently, the $A E$ index increases again to a maximum value of $1200 \mathrm{nT}$ around 08:00 UT (17:00 JST on 12 February 2000) and undergos oscillations by keeping higher values with 18:00 UT.

Figure 2 represents the contours for latitudinal and temporal variations of (a) TEC, and (b) the storm-time TEC enhancements on 12 February 2000, compared to a quiet-time reference. The values of TEC around 03:00 UT at $32^{\circ} \mathrm{N}$ and $39^{\circ} \mathrm{N}$ are approximately $90 \times 10^{16}$ electrons $/ \mathrm{m}^{2}$ and $65 \times 10^{16}$ electrons $/ \mathrm{m}^{2}$, respectively (Fig. 2a). This implies that high values of background content and latitudinal gradient of TEC exist at the low-latitude region.

The storm-time TEC enhancements on 12 February 2000 were derived by subtracting the quiet-time TEC (reference) from the storm-time TEC. The TEC enhancement with respect to the quiet-time reference (Fig. $2 b$ ) propagates towards the south with an approximate propagation velocity of $550 \mathrm{~m} / \mathrm{s}$ after 02:00 UT (11:00 JST), whose maximum magnitude is $40 \mathrm{TECU}$, and then undergoes considerable reduction in magnitude after $36^{\circ} \mathrm{N}\left(27^{\circ} \mathrm{N}\right.$ geomagnetically). A black line is included in Fig. $2 b$ to indicate 
12 February 2000

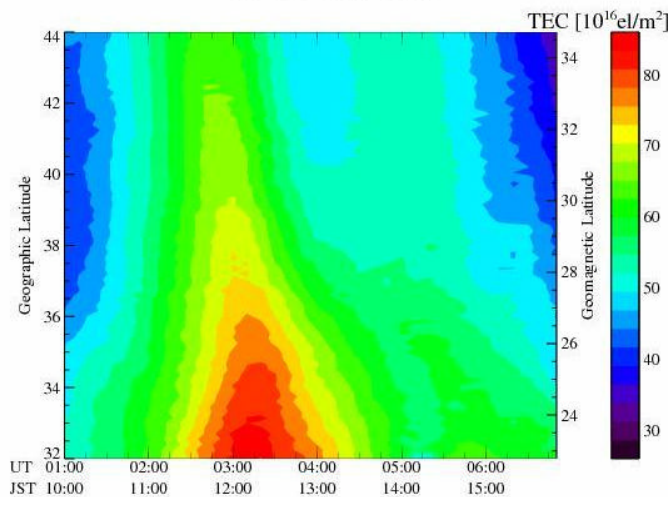

12 February 2000

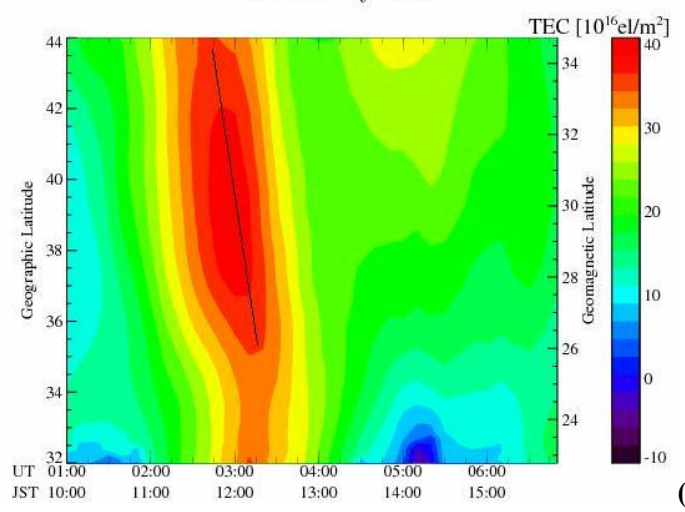

(b)

Fig. 2. The contours for latitudinal and temporal variations of (a) TEC, and (b) TEC enhancements on 12 February 2000 compared to quiet-time (reference) values. The line drawn in this figure indicates the southward trend of propagation of TEC enhancements compared to quiet-time (reference) values.

the trend, to clarify the southward propagation. Another enhancement with maximum magnitude 28 TECU is seen after 04:30 UT (13:30 JST), whose propagation velocity is nearly $370 \mathrm{~m} / \mathrm{s}$. Its magnitude also reduces close to $38^{\circ} \mathrm{N}\left(29^{\circ} \mathrm{N}\right.$ geomagnetically). However, at the low-latitude region, below $34^{\circ} \mathrm{N}\left(25^{\circ} \mathrm{N}\right.$ geomagnetically), an increase in TEC is manifested (Fig. 2b) as an enhanced ionization pattern (EIP) after 02:30 UT (11:30 JST).

Figure 3 shows the contours for latitudinal and temporal variations of (a) TEC, and (b) the perturbation component of TEC, $(\triangle T E C)$ on 13 February 2000 . The same parameters (TEC and perturbation component) are also plotted on the other storm days, such as 23 September 1999 (Figs. 3c and d, respectively), 29 October 2003 (Figs. 3e and f, respectively), and 21 November 2003 (Figs. 3g and h, respectively). The perturbation components of TEC for this study were derived by subtracting the background TEC from the absolute TEC. The background TEC values $\left(\mathrm{TEC}_{0}\right)$ for this study were derived by finding the running average of absolute TEC for suitable periods. The period of the running average was selected according to the typical periods of the perturbations on 12 February 2000. These data (perturbation components) of the above dates can clearly present the TEC behavior during the above storm days (without any quiettime reference), whose scale sizes are comparable to that on 12 February 2000. Also, it is often difficult to find appropriate quiet days for reference during geomagnetically disturbed periods.

Figure $3 \mathrm{~b}$ exhibits the perturbation component observed at 06:00 UT on 13 February 2000, with maximum value $8 \mathrm{TECU}$, which propagates from the north $\left(44^{\circ} \mathrm{N}\right)$ to the south with a propagation velocity $480 \mathrm{~m} / \mathrm{s}$. It is seen that the magnitude of this perturbation component decreases around $35^{\circ} \mathrm{N}$. However, at the low-latitude region, below $34^{\circ} \mathrm{N}$, an enhanced ionization pattern (EIP) is observed around 07:00 UT (Fig. 3b). On the same day, a similar phenomenon (EIP) is also seen at the low-latitude region (below $34^{\circ} \mathrm{N}$ ) around 02:30 UT and 04:30 UT (Fig. 3b). On 23 September 1999, the perturbation component (with maximum value $8 \mathrm{TECU}$ ) propagates from the northern region up to $38^{\circ} \mathrm{N}$, and thereafter suffers a considerable decrease in magnitude (Fig. 3d). On 29 October 2003, this parameter has a maximum value of $7 \mathrm{TECU}$, which propagates more southward (compared to other days) and reduces considerably around $34^{\circ} \mathrm{N}$ (Fig. 3f). This may be due to the fact that the latitudinal gradient of TEC during the same time is appreciable only up to $34^{\circ} \mathrm{N}$ (Fig. 3e), which is blocking this propagation component (Fig. 3f). On this day, at the low-latitude region, around $32^{\circ} \mathrm{N}-34^{\circ} \mathrm{N}$, EIP features are observed around 07:30 UT and 10:00 UT (Fig. 3f). On 11 November 2003, the TEC perturbation decreases around $35^{\circ} \mathrm{N}$ (Fig. 3h). In the perturbation figures (Figs. 3b, d, f, and h), we have included black lines with the slopes corresponding to the southward movements, and the slopes of these black lines are given in the corresponding figure captions. The TEC values at low latitudes (southern region) on the above dates (Figs. 3a, c, e, and g) are high enough to restrict the perturbation components, which are propagating from north to south (Figs. 3b, $\mathrm{d}, \mathrm{f}$, and $\mathrm{h}$ ). This indicates that the latitudinal sector of the present study is a transition region for TEC enhancements, due to the mutual interaction between the perturbation component (presented in Figs. 3b, d, f, and h) and the opposition offered by the high background content at the low latitude (presented in Figs. 3a, c, e, and g), due to the influence of the anomaly crest.

Amplitudes of the TEC enhancements were defined as $\left|\left(\Delta \mathrm{TEC}_{\max }-\Delta \mathrm{TEC}_{\min }\right)\right| / \mathrm{TEC}_{0}$. The latitudinal variations of the amplitudes of TEC enhancements are plotted as triangles in Fig. 4. The latitudinal damping rate was found from the gradients of the least-squares fitted lines drawn in Fig. 4. Since the amplitudes are rapidly decreasing over the 39$34^{\circ} \mathrm{N}$ region, we calculated the damping rates at two latitude sectors, $44-39^{\circ} \mathrm{N}$ and $39-34^{\circ} \mathrm{N}$, separately. On 12 February 2000 , the damping rate at $39-34^{\circ} \mathrm{N}$ is $0.0775 / \mathrm{deg}$ and that at 


\section{February 2000}

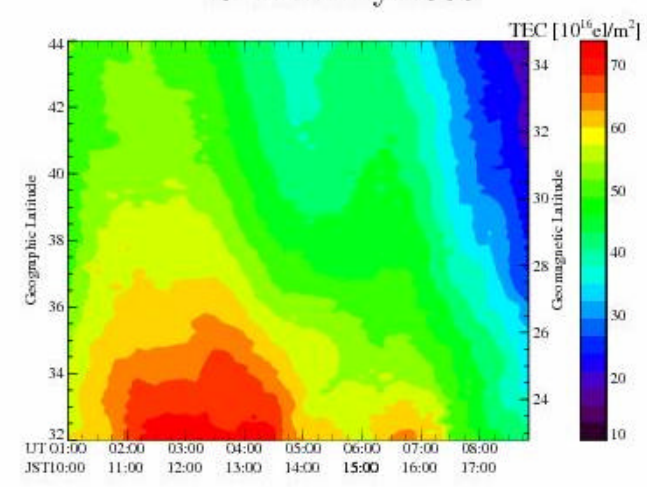

(a)

\section{September 1999}

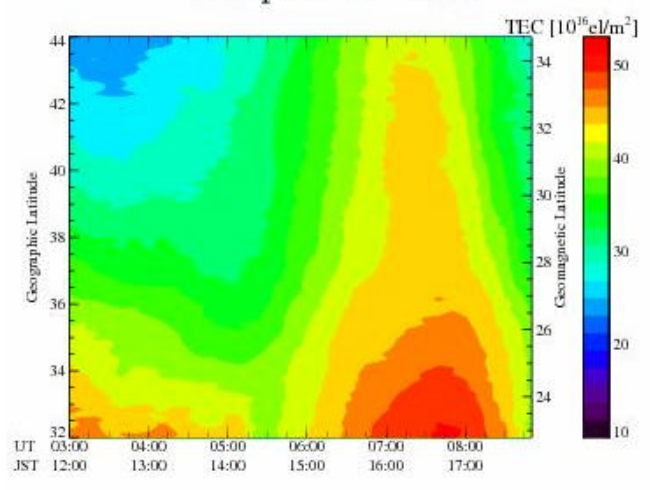

13 February 2000

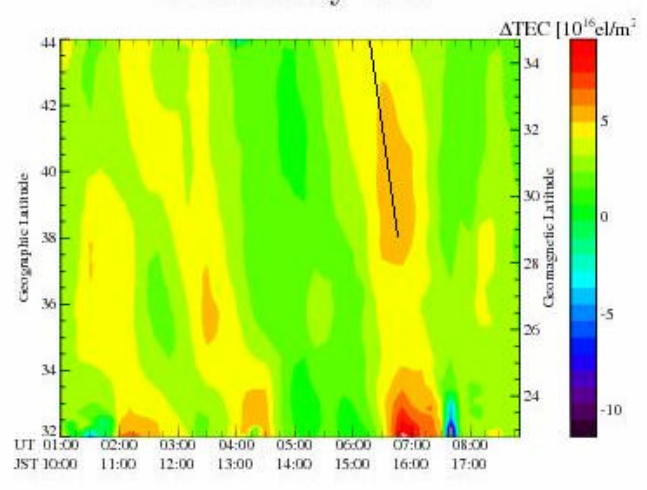

(b)

\section{September 1999}

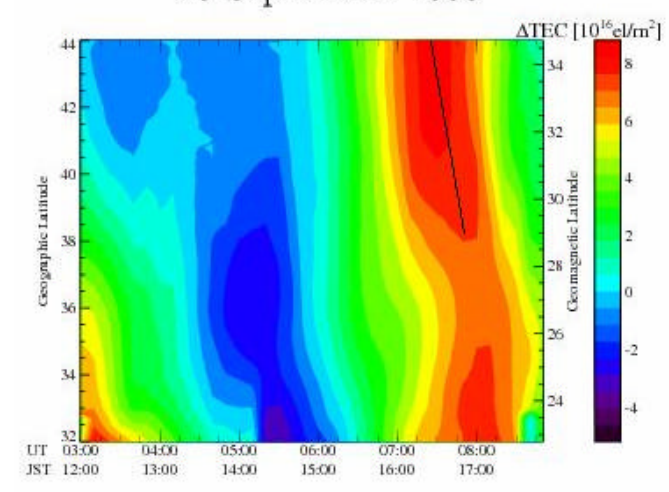

(d)

Fig. 3. The contours for latitudinal and temporal variations of (a) TEC and (b) the perturbation component of TEC on 13 February 2000. The same parameters (TEC and the perturbation component of TEC) are also plotted on the other storm days, such as, 23 September 1999: (c) and (d), respectively, 29 October 2003: (e), (f), respectively, and 21 November 2003: (g) and (h), respectively. In Fig. 3b, the black line drawn with the slope $=0.0043 \mathrm{deg} / \mathrm{s}$ indicates the southward movement of the perturbation component on 13 February 2000 . Similarly, the southward movement of the perturbation component on 23 September 1999 (Fig. 3d), 29 October 2003 (Fig. 3f), and 21 November 2003 (Fig. 3h), are indicated by black lines with the slopes $0.005,0.0056$, and $0.0066 \mathrm{deg} / \mathrm{s}$, respectively.

$44-39^{\circ} \mathrm{N}$ is $0.0052 / \mathrm{deg}$ (Fig. 4a). Similarly, on 23 September 1999, the values of this parameter over the regions, $39-34^{\circ} \mathrm{N}$ and $44-39^{\circ} \mathrm{N}$, are, respectively, $0.0577 / \mathrm{deg}$ and $0.0155 /$ deg (Fig. 4b). However, on 29 October 2003, the values of this parameter over the above latitude sectors are, respectively, 0.0506/deg and 0.0429/deg (Fig. 4c). It clarifies quantitatively that the propagating perturbation components undergo a transition/decrease at the low-latitude sector, mainly due to the restrictions offered by the high background content at that region.

Figure $5 \mathrm{~b}$ shows the increase in the F-layer virtual height on 12 February 2000 compared to the quiet-time values observed by the ionosonde data at Kokubunji $\left(35.7^{\circ} \mathrm{N}\right.$, $\left.139.5^{\circ} \mathrm{E}\right)$ and Wakkanai $\left(45.4^{\circ} \mathrm{N}, 141.7^{\circ} \mathrm{E}\right)$. The maximum increase in the F-layer height observed at Wakkanai (at $1100 \mathrm{JST}$ ) is $1 \mathrm{~h}$ earlier than that observed at Kokubunji (at 12:00 JST), which is approximately $20 \mathrm{~km}$ compared to their respective previous hour values. Similarly, foF2 values at Kokubunji and Wakkanai (Fig. 5a) exhibit an increase by a factor of $3 \mathrm{MHz}$ (at 12:00 JST). Another increase in $f_{o} \mathrm{~F} 2$ is also observed at Wakkanai by a factor of $2 \mathrm{MHz}$, around 14:00 JST. On 29 October 2003, the F-layer height increased by more than $150 \mathrm{~km}$ at Wakkanai and $90 \mathrm{~km}$ at Kokubunji, around 18:00 JST with respect to quiet-time values (Fig. 5d). These changes in the $f o \mathrm{~F} 2$ values at Kokubunji and Wakkanai are, respectively, $3.5 \mathrm{MHz}$ (at 20:00 JST) and $1 \mathrm{MHz}$ (at 21:00 JST).

\section{Discussion}

The equatorial plasma fountain, responsible for the equatorial ionization anomaly (EIA) formation, could undergo a significant enhancement, or inhibition, under the action of the disturbance electric fields during the storms. The disturbance fountain covers a much wider latitudinal belt than the normal fountain driven by the E-/F-layer dynamo electric field. The formation of latitudinally displaced crests of expanded anomaly results from the diffusion process that follows the initial disturbance fountain associated EIA 
29 October 2003

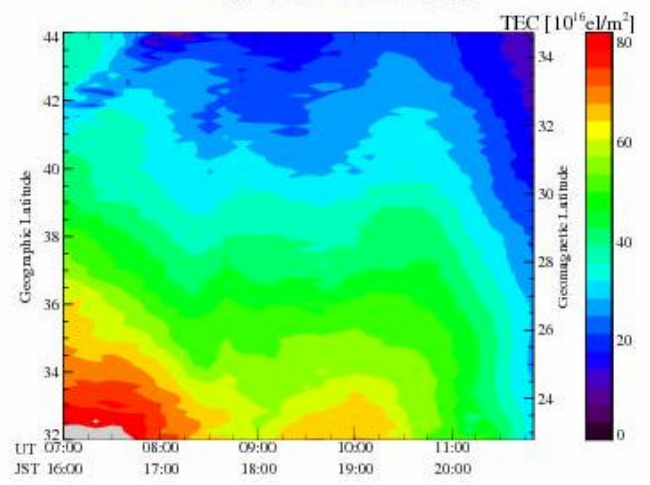

(e)

21 November 2003

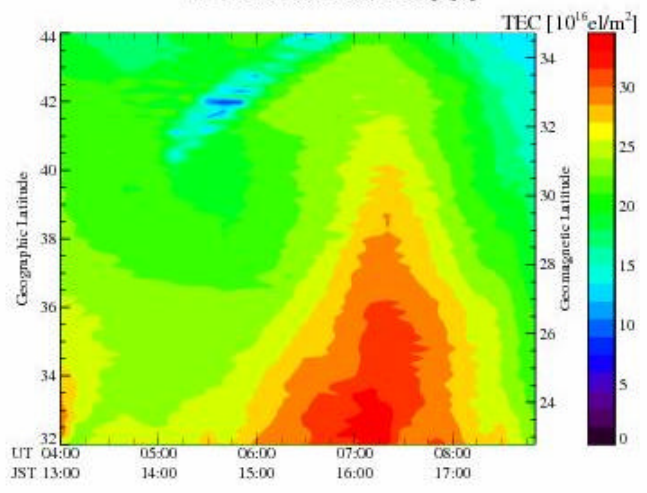

29 October 2003

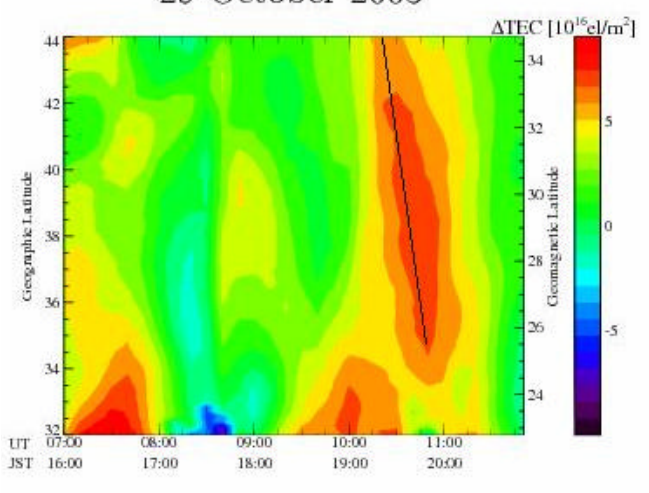

(f)

(g)

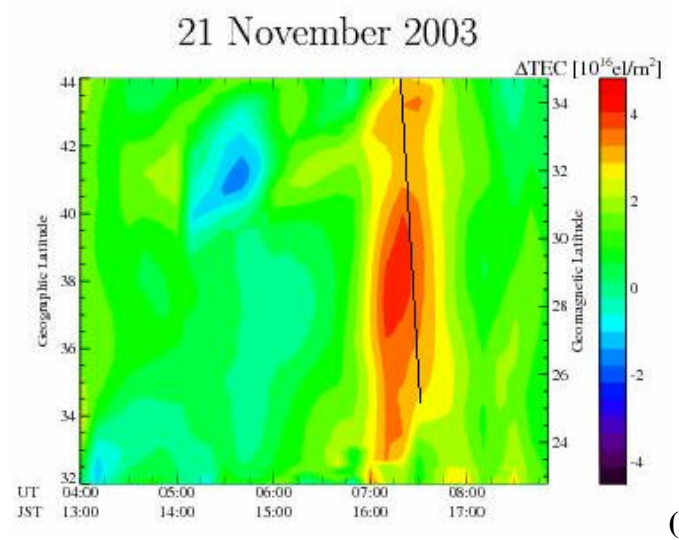

(h)

Fig. 3. Continued.

expansion (Abdu, 1997). In the case of both intense and weak storms, the poleward expansion of EIA is caused by the PP eastward electric field and the contraction of EIA is caused by the disturbance westward electric field (Abdu, 1997; Pincheria et al., 2002; Tsurutani et al., 2004). In the present study, IMF $B_{z}$ becomes predominantly southward and attains a maximum value of $-18 \mathrm{nT}$ around 23:00 UT on 11 February 2000 (08:00 JST, on 12 February 2000) and continues the same trend for the next few hours with oscillations. After changing the direction towards the north, IMF $B_{z}$ again becomes southward after 06:00 UT (15:00 JST) on 12 February 2000. Subsequently, due to the influence of the southward IMF $B_{z}$, the $A E$ index shows a maximum value of about 1200 nT around 00:00 UT (09:00 JST) on 12 February 2000, and continues to be higher for the next few hours. After showing a decrease, it increases again to a maximum value of 1200 nT around 08:00 UT (17:00 JST on 12 February 2000) and undergoes small oscillations by keeping higher values until 18:00 UT. This could be the evidence for a PP eastward electric field causing the TEC enhancements at the low-latitude region, manifesting as an enhanced ionization pattern (EIP) on 12 February 2000, which is also repeated on other storm days studied here.
At low latitudes (away from the magnetic equator) the F-layer height response to the electric field is significantly modified by the existing conditions, of the meridional wind. Changes in the ionospheric heights with respect to their quiet-time pattern at low latitudes are produced by vertical plasma drifts driven by (a) magnetospheric electric fields penetrating to equatorial latitudes, (b) disturbance dynamo electric fields, and (c) disturbance meridional winds. At low latitudes (away from the magnetic equator) the meridional wind, $\boldsymbol{U}$, can contribute to the F-layer vertical drift by a factor of $U^{*} \cos (I)^{*} \sin (I)$, (where $I$ is the dip angle), such that the observed changes in the vertical drift/F-layer height in response to a given amplitude of the disturbance electric field could be amplified or diminished, depending on the direction of the winds (equatorward or poleward) and the dip angle $(I)$ of the location (Abdu et al., 1995; Abdu, 1997). The contribution of the meridional neutral wind will be maximum, if the dip angle is $45^{\circ} \mathrm{N}$. In the Japanese sector, $32^{\circ} \mathrm{N}$ of geographic latitude is the location of the $45^{\circ} \mathrm{N}$ dip angle. Therefore, the decrease in amplitude and magnitude of the polar-originated enhancements around the $36^{\circ} \mathrm{N}$ latitude may be caused by the weakening of the storm associated neutral wind and its influence on the F-layer vertical drift. 
12 February 2000

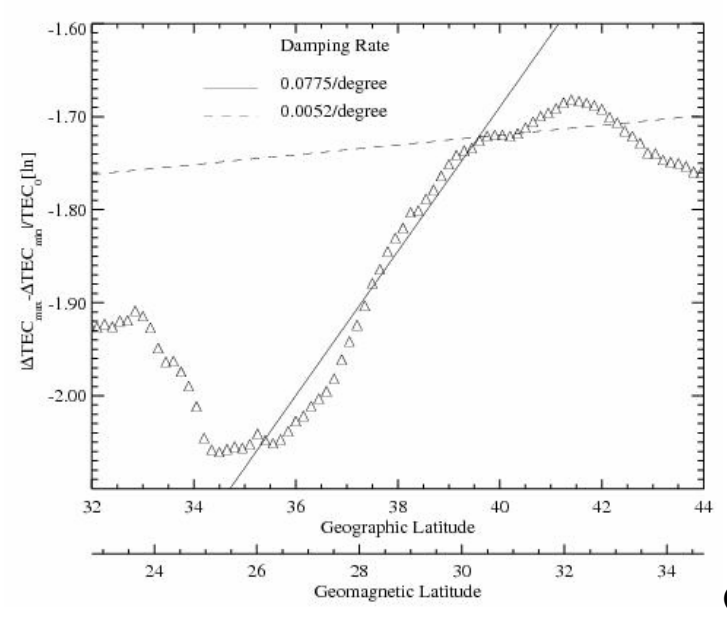

23 September 1999

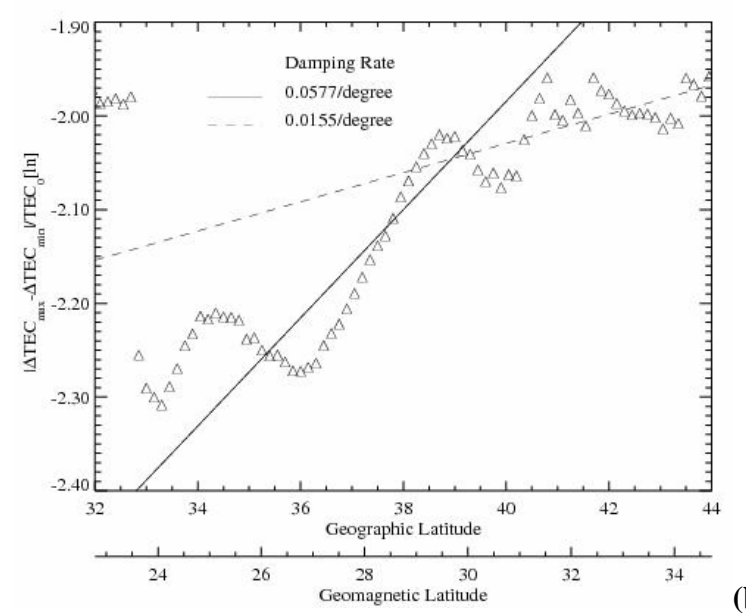

(b)

29 October 2003

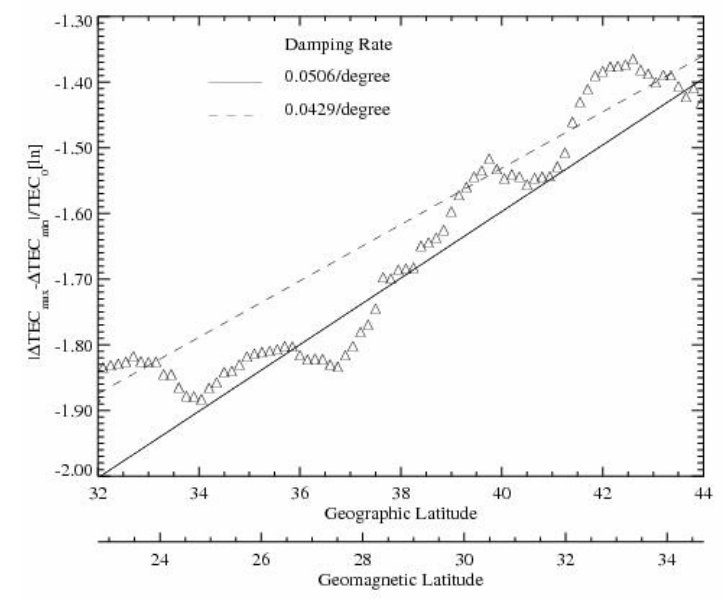

(c)

Fig. 4. The latitudinal variations of the amplitudes of TEC enhancements, $\left|\left(\Delta \mathrm{TEC}_{\max }-\Delta \mathrm{TEC}_{\min }\right)\right| / \mathrm{TEC}_{0}$, are plotted as triangles on (a) 12 February 2000, (b) 23 September 1999, and (c) 29 October 2003. The latitudinal damping rate was found from the gradients of the least-squares fitted lines drawn at latitude sectors $44-39^{\circ} \mathrm{N}$ (dashed line) and $39-34^{\circ} \mathrm{N}$ (continuous line), separately.

It is known that the equatorward winds, driven by the increase in Joule and particle heating, push the ionospheric layers to greater altitudes and across pressure surfaces. Within this new regime of neutral composition, where fewer molecular species are present, the ionosphere is slower to recombine, and positive ionospheric changes are observed (Prölss, 1995; 1997). On 12 February 2000, the time of occurrence of the increase in F-layer height (approximately $20 \mathrm{~km}$ each compared to their respective previous hour values) observed at Wakkanai (at 11:00 JST) is one hour earlier than that observed at Kokubunji (at 12:00 JST). Hence, the F-layer height variations at Wakkanai and Kokubunji are showing a dispersion feature of LSTID or passage of an equatorward surge. The slight time delay between the maximization of TEC and the ionosonde values may be due to the fact that the temporal resolution of GPS-TEC data is $30 \mathrm{~s}$ and that of ionosonde data is one hour. Another factor is that, depending upon lo- cal time and pre-storm conditions, the maximum response of $f_{o} \mathrm{~F} 2$ to PP electric field could have a delay of $1-3 \mathrm{~h}$ (Abdu, 1997; Pincheira et al., 2002).

A storm-time increase in $f o \mathrm{~F} 2$ values on 12 February 2000 with respect to quiet-time values are observed at Kokubunji and Wakkanai by $3 \mathrm{MHz}$ (at 12:00 JST) each. The time of occurrence of the increase in F-layer height and $f o \mathrm{~F} 2$ observed at Wakkanai and Kokubunji are matching with the time of observation of the TEC enhancement, which is propagating from the north to the south around 12:00 JST. Another increase in $f o \mathrm{~F} 2$ is observed at Wakkanai by a factor of $2 \mathrm{MHz}$, around 14:00 JST, and is not seen at Kokubunji, also matching with the time of TEC enhancement observed at the north (around 14:00 JST), which is being restricted near $38^{\circ} \mathrm{N}$ (Fig. 2b). These observations imply the role of the equatorward neutral wind, which increases the F-layer height, by lifting the ionization to the regions of lower loss during the 
12 February 2000

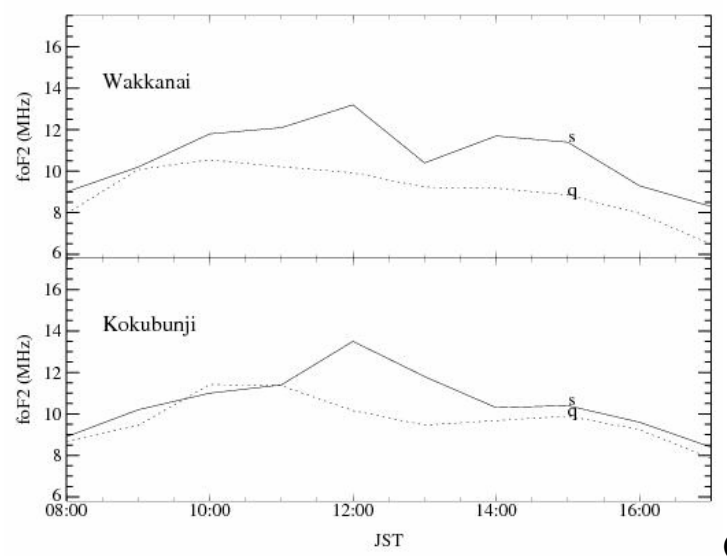

(a)

29 October 2003

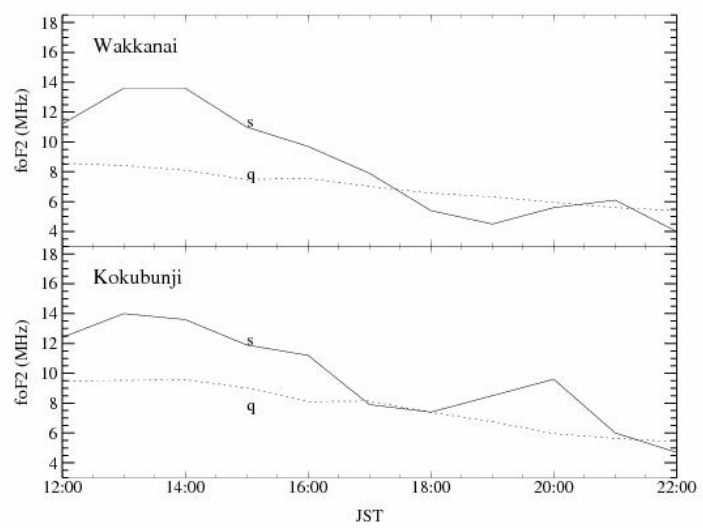

(c)
12 February 2000

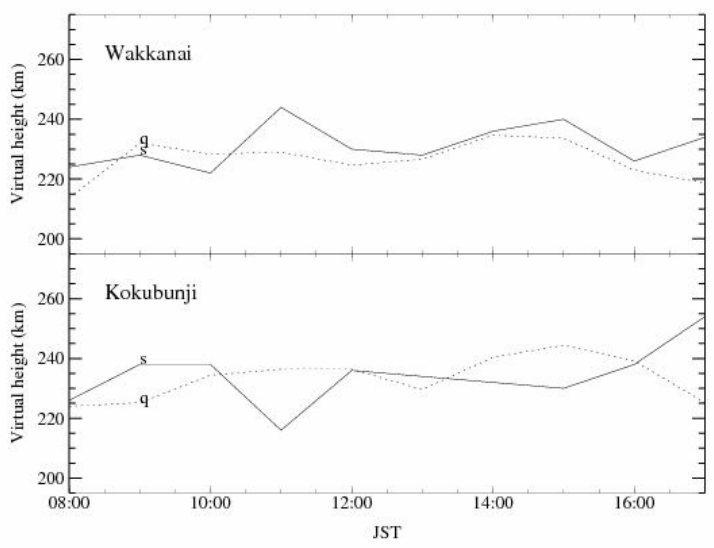

(b)

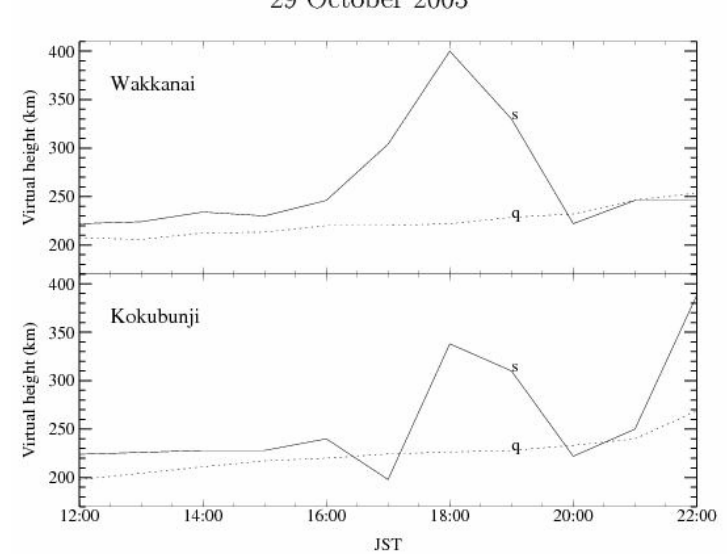

(d)

Fig. 5. Temporal variations of (a) $f o F 2$, and (b) F-layer virtual height on 12 February 2000 (continuous line with a marking "s") compared to the quiet-time values (dotted line with a marking “q”) observed by ionosonde data at Kokubunji $\left(35.7^{\circ} \mathrm{N}, 139.5^{\circ}, \mathrm{E}\right)$, and Wakkanai $\left(45.4^{\circ} \mathrm{N}\right.$, $141.7^{\circ}$ E). Also, those of (c) $f o F 2$, and (d) F-layer virtual height on 29 October 2003.

daytime, when production is still taking place, which, in turn, increases the TEC values.

On 29 October 2003, the F-layer height is increased by more than $150 \mathrm{~km}$ at Wakkanai and $90 \mathrm{~km}$ at Kokubunji around 18:00 JST, with respect to their quiet-time values, which indicates the presence and influence of the equatorward neutral wind (Fig. 5d). Simultaneously, TEC perturbation observed at the northern region, after 18:30 JST, which propagates towards the south (Fig. 3f), could be caused mainly by this equatorward neutral wind, which produced the observed increase in the F-layer height.

It is known that the period, phase velocity and the perturbation component for Disturb Time Damping LSTIDs were $75 \pm 22 \mathrm{~min}, 485 \pm 145 \mathrm{~m} / \mathrm{s}$, and $1.3 \pm 0.7 \mathrm{TECU}$ (Tsugawa et al., 2004). Even though the other parameters are much higher, the phase velocity of the propagation of the TEC enhancement on 12 February 2000, observed in the present study $(550 \mathrm{~m} / \mathrm{s})$, is comparable with those of LSTIDs $(487 \pm 145 \mathrm{~m} / \mathrm{s})$. This implies that the wave front of propagation of the observed TEC enhancement may be con- tributed to by the LSTID. However, LSTIDs could not produce large TEC perturbations (Tsugawa et al., 2003, 2004), as observed in the present study ( $\geq 7 \mathrm{TECU}$, with duration $\geq 120 \mathrm{~min}$ ), which are propagating from the north to the south. Hence, it is reasonable to believe that a combined effect of an increase in F-layer height, caused by the equatorward neutral wind and the LSTID during sunlit conditions, is contributing to the observed effects. This study shows that, during day sectors of major storms, TEC perturbations over Japanese mid-latitudes are initiated at the northern region, propagate towards the south and undergo transitions by exhibiting a decrease in amplitude and magnitude as they reach $39-34^{\circ} \mathrm{N}$, due to the restrictions offered by the high background content at the southern region, due to the anomaly crest.

The characteristics of the mid-latitude ionosphere are generally determined by the diurnal, seasonal and solar cycle variations. However, during large disturbances, this regular and predictable variability can be dramatically overturned, as the forces which drive the high-latitude regime expand equa- 
torward or by the poleward expansion of equatorial ionization anomaly (EIA). In the case of perturbation at 03:00 UT on 12 February 2000, it is seen that TEC enhancements occur simultaneously at the southern region below $36^{\circ} \mathrm{N}$ (Fig. 2b), a characteristic of TEC enhancements caused by the intensification of the eastward electric field. However, the TEC enhancements caused by the mechanisms which originate at the polar regions (disturbed neutral wind system) are characterized by the equatorward propagation (at the northern region above $36^{\circ} \mathrm{N}$ ). It is to be noted that the duration of the intensification of the TEC enhancement at the southern latitude is around 03:00-03:15 UT, which is almost same as that of the intensification of the TEC enhancement observed at the north (Fig. 2b). The disturbed neutral wind and the disturbed equatorial electric field often work simultaneously, because both mechanisms are modulated by the storm-time energy inputs. But unlike the previous case, the perturbation at 04:30 UT, caused by the polar originated mechanisms (disturbed neutral wind system), reduces its magnitude considerably around $38^{\circ} \mathrm{N}$, and is not supported by the disturbed equatorial electric field, thereafter.

It is observed that, when the perturbation component/TEC enhancement attempts to penetrate the regions of high background content, its strength may reduce to a certain extent (Fig. 2b). This is because the expanded equatorial anomaly crest is characterized by high-density plasma, with steep latitudinal gradients in TEC, which will offer higher resistance to the equatorward propagation of the perturbation component. The quantitative aspects of this transition phenomenon exhibit that on 12 February 2000, the amplitude of the TEC enhancement decreases rapidly with a damping rate of 0.0775 at $39-34^{\circ} \mathrm{N}$, which is much higher than that at 44$39^{\circ} \mathrm{N}(0.0052 / \mathrm{deg})$ (Fig. 4a). Similarly, the damping rate on 23 September 1999 , at $39-34^{\circ} \mathrm{N}(0.0577 / \mathrm{deg})$, is more than three times that observed at $44-39^{\circ} \mathrm{N}(0.0155 / \mathrm{deg})$.

\section{Summary}

By using a high-resolution GPS network over Japan, stormassociated, large-scale TEC perturbations observed during the day sectors of major storm periods, 12-13 February 2000; 23 September 1999; 29 October 2003 and 21 November 2003, were studied. TEC enhancements described in the present study are quite different from the previous studies based on LSTIDs, because of the much higher perturbation component $(\geq 7$ TECU), period $(\geq 120 \mathrm{~min})$ and amplitude ( $\geq 25$ TECU) of TEC enhancements observed here, compared to those of LSTIDs. The sequential manner of development and the propagation of these perturbations show that they are initiated at the northern region and propagate towards the southern region of Japan, with velocities $>350 \mathrm{~m} / \mathrm{s}$. On 12 February 2000, remarkably high values of TEC and background content are observed at the southern region, compared to the north, because of the poleward expansion of the equatorial anomaly crest, which is characterized by strong latitudinal gradients near $35^{\circ} \mathrm{N}\left(26^{\circ} \mathrm{N}\right.$ geomagnet- ically). When the TEC enhancements, initiating at the north, propagate through the region $39-34^{\circ} \mathrm{N}\left(30-25^{\circ} \mathrm{N}\right.$ geomagnetically), they undergo transitions characterized by a severe decrease in amplitude of the TEC enhancements. This may be due to the restrictions offered by the high background TEC of the expanded anomaly crest. However, at the lowlatitude region, below $34^{\circ} \mathrm{N}$, an increase in TEC is manifested as an enhanced ionization pattern (EIP). This could be due to the prompt penetration of the eastward electric field, which is evident from high values of the southward Interplanetary Magnetic Field component (IMF $B_{z}$ ) and the $A E$ index.

The TEC perturbations observed on the other storm days also exhibit the similar transitions by decreasing the magnitude of the perturbation component at the region $39-34^{\circ} \mathrm{N}$ (30-25 $\mathrm{N}$ geomagnetically). In addition to this, on the other storm days, at the low-latitude region, below $34^{\circ} \mathrm{N}$, an increase in TEC (EIP feature) also indicates the repeatability of the above scenario. It is found that the latitude and time at which the decrease in the magnitude of the perturbation component/amplitude of the TEC enhancement are matching the latitude and the time of appearance of the high background content. This indicates that the latitudinal sector of the present study is a transition region for TEC enhancements, due to the mutual interaction between the perturbation component and the opposition offered by high background content, due to the influence of anomaly crest. The quantitative aspects of the TEC enhancements studied here also generally clarify the above observations.

On 12 February 2000, the F-layer height increases at Wakkanai, and Kokubunji by exhibiting a typical dispersion feature of LSTID or passage of an equatorward surge. On 29 October 2003, the F-layer height increased by more than $150 \mathrm{~km}$ at Wakkanai and $90 \mathrm{~km}$ at Kokubunji, around 18:00 JST, which could be due to the influence of the equatorward neutral wind. The time of occurrence of an increase in the F-layer height and $f o \mathrm{~F} 2$ observed at Wakkanai and Kokubunji are matching the time of observation of the TEC enhancements observed on these days, which are propagating from the north to the south. These observations imply the role of the equatorward neutral wind, which increases the Flayer height, by lifting the ionization to the regions of lower loss during the daytime, when production is still taking place, which in turn increases the TEC values.

Even though the other parameters, such as the perturbation component and period, are much higher, the phase velocity of the propagation of the TEC enhancement on 12 February 2000 , observed in the present study $(550 \mathrm{~m} / \mathrm{s})$, is comparable with those of the LSTIDs observed in the previous studies $(487 \pm 145 \mathrm{~m} / \mathrm{s})$. This implies that the wave front of propagation of the observed TEC enhancement may be contributed to by LSTID. However, LSTIDs could not produce large TEC perturbations as observed in the present study ( $\geq 7$ TECU) with a duration $\geq 120 \mathrm{~min}$. A combined effect of an increase in the F-layer height, caused by the equatorward neutral wind, and the LSTID, are contributing to the observed effects. 
Acknowledgements. K. Unnikrishnan's research in Research Institute for Sustainable Humanosphere (RISH), Kyoto University, Japan, is supported by Japan Society for the Promotion of Science (JSPS) Postdoctoral Fellowship for foreign researchers. A. Saito acknowledge the Geographical Survey Institute, Japan for providing GEONET data used in the present study. We express our sincere thanks to National Institute of Information and Communication Technology (NICT), Japan for providing ionosonde data. Also, we thank the ACE MAG instrument team and the ACE Science Center for providing the ACE data.

Topical Editor M. Pinnock thanks J. H. A. Sobral and another referee for their help in evaluating this paper.

\section{References}

Aarons, J.: Global positioning system phase fluctuations at auroral latitudes, J. Geophys. Res., 102, 17 219-17 231, 1997.

Abdu, M. A., Batista, I. S., Walker, G. O., Sobral, J. H. A., Trivedi, N. B., and de Paula, E. R.: Equatorial electric fields during magnetospheric disturbances: Local time/longitude dependencies from recent EITS campaigns, J. Atmos. Terr. Phys., 57, 1065-1072, 1995.

Abdu, M. A.: Major phenomena of the equatorial ionospherethermosphere system under disturbed conditions, J. Atmos. Solar. Terr. Phys., 59, 1505-1519, 1997.

Balan, N., Bailey, G. J., and Balachandran Nair, R.: Solar and magnetic activity effects on the latitudinal variations of night-time TEC enhancement, Ann. Geophys., 9, 60-69, 1991.

Basu, S., Basu, S., Valladares, C. E., Yeh, H.-C., Su, S.-Y., MacKenzie, E., Sultan, P. J., Aarons, J., Rich, F. J., Dohetry, P., Groves K. M., and Bullett, T. W.: Ionospheric effect of major magnetic storms during the International Space Weather Period of September and October 1999, GPS observations, VHF/UHF Scintillations, and in situ density structures at middle and equatorial latitudes, J. Geophys. Res., 106, 30 389-30 413, 2001.

Beach, T. L., Kelley, M. C., Kinter, P. M., and Miller, C.: Total electron content variations due to nonclassical traveling ionospheric disturbances: Theory and Global Positioning System observations, J. Geophys. Res. 102, 7279-7292, 1997.

Blanc, M.: Magnetospheric convection effects at mid-latitudes, 1, Saint Santin observations, J. Geophys. Res., 88, 2211-2223, 1983.

Buonsanto, M. J.: A case study of ionospheric storm dusk effect, J. Geophys. Res, 100, 23 857-23 869, 1995.

Buonsanto, M. J.: Ionospheric storms - a review, Space Science Reviews, 88, 563, 1999.

Fejer, B. G. and Scherliess, L.: Mid- and low-latitude promptpenetration ionospheric zonal plasma drifts, Geophys. Res. Lett., 25, 3071-3075, 1998.

Field, R. P. and Rishbeth, H.: The response of the ionospheric F2layer to geomagnetic activity: an analysis of world wide data, J. Atmos. Solar. Terr. Phys., 59, 163-183, 1997.

Forbes, J. M.: Evidence for the equatorward penetration of electric fields, winds, and compositional effects in the Asian/Pacific sector during the 17-24 September, 1984, ETS interval, J. Geophys. Res., 94, 16999-17 007, 1989.

Foster, J. C.: Storm time plasma transport at middle and higher latitudes, J. Geophys. Res., 98, 1675-1689, 1993.

Fukao, S., Kelley, M. C., Shirakawa, T., Takami, T., Yamamoto, M., Tsuda, T., and Kato, S.: Turbulent upwelling of the mid-latitude ionosphere, 1. observational results by the MU radar, J. Geophys. Res., 96, 3725-3746, 1991.

Fuller-Rowell, T. J., Codrescu, M. V., Moffett, R. J., and Quegan, S.: Response of the thermosphere and ionosphere to geomagnetic storms, J. Geophys. Res., 99, 3893-3914, 1994.

Fuller-Rowell, T. J., Codrescu, M. V., Rishbeth, H., Moffett, R. J., and Quegan, S.: On the seasonal response of the thermosphere and ionosphere to geomagnetic storms, J. Geophys. Res., 101, 2343-2353, 1996.

Garcia, F. J., Kelley, M. C., Makela, J. J., and Huang, C. S.: Airglow observations of mesoscale low-velocity traveling ionospheric disturbances at mid latitudes, J. Geophys. Res., 105, 18 407-18 416, 2000.

Ho, C. M., Mannucci, A. J., Lindqwister, U. J., Pi, X., and Tsurutani, B. T.: Global ionosphere perturbations monitored by the world wide GPS network, Geophys. Res. Lett., 23, 3219-3222, 1996.

Huang, Y. N. and Cheng, K.: Ionospheric disturbances around East Asian region during the 20 October 1989 magnetic storms, J. Atmos. Solar-Terr. Phys., 55, 1009-1020, 1993.

Huang, C. S., Foster, J. C., and Erickson, P. J.: Effects of solar wind variations on the midlatitude ionosphere, J. Geophys. Res., 107, (A8), doi:1029/2001JA00905, 2002.

Kelley, M. C., Kotsikopoulos, D., Beach, T., Hysell, D., and Musman, S.: Simultaneous Global Positioning System and radar observations of equatorial spread F at Kwajalein, J. Geophys. Res., 101, 2333-2341, 1996.

Kutiev, I. and Muhtarov, P.: Empirical modeling of global ionospheric $\mathrm{f}_{o} \mathrm{~F}_{2}$ response to geomagnetic activity, J. Geophys. Res., 108(A1), 1021, doi:10.1029/2001JA009134, 2003.

Mendillo, M., Papagiannis, M. D., and Klobuchar, J. A.: Average behavior of F-region parameters $\mathrm{N}_{T}, \mathrm{~N}_{\max }$, and $\tau$ during geomagnetic storms, J. Geophys. Res., 77, 4891-4895, 1972.

Miller, C. A., Swartz, W. E., Kelley, M. C., Mendillo, M., Nottingham, D., Scali, J., and Reinisch, B.: Electrodynamics of midlatitude spread $F 1$. Observations of unstable, gravity wave induced ionospheric electric fields at tropical latitudes, J. Geophys. Res., 102, 11 521-11 532, 1997.

Musman, S., Jahn, J. M., LaBelle, J., and Swartz, W. E.: Imaging spread- F structures using GPS observations at Alcantara, Brazil, Geophys. Res. Lett., 24, 1703-1706, 1997.

Otsuka, Y., Ogawa, T., Saito, A., Tsugawa, T., Fukao, S., and Mayazaki, S.: A new technique for mapping of total electron content using GPS network in Japan, Earth Planets Space., 54, 63-70, 2002.

Pincheira, X. T., Abdu, M. A., Batista, I. S., and Richards, P. G.: An investigation of ionospheric responses, and disturbance thermospheric winds, during magnetic storms over South American sector, J. Geophys. Res., 107(A11), 1379, doi:10.1029/2001JA000263, 2002.

Prölss, G. W.: Ionospheric F-region storms hand book of atmospheric electrodynamics, vol. 2, CRC Press, Boca Raton, Fla. 195-248, 1995.

Prölss, G. W.: Magnetic storm associated perturbations of the upper atmosphere, Magnetic Storms, Geophysical monograph 98, 227, 1997.

Saito, A., Fukao, S., and Mayazaki, S.: High resolution mapping of TEC perturbations with the GSI GPS network over Japan, Geophys. Res. Lett., 25, 3079-3082, 1998.

Saito, A., Nishimura, M., Yamamoto, M., Fukao, S., Kubota, M., Shiokawa, K., Otsuka, Y., Tsugawa, T., Ogawa, T., Ishii, M., Sakanoi, T., and Miyazaki, S.: Traveling ionosphereic distur- 
bances detected in the FRONT campaign, Geophys. Res. Lett., 28, 689-692, 2001.

Saito, A., Nishimura, M., Yamamoto, M., Fukao, S., Tsugawa, T., Otsuka, Y., Mayazaki, S., and Kelley, M. C.: Observations of traveling ionosphereic disturbances and 3-m scale irregularities in the night time F-region ionosphere with the MU radar and a GPS network, Earth Planets Space, 54, 31-44, 2002.

Sobral, J. H. A., Abdu, M. A., Gonzalez, W. D., Tsurutani, B. T., Batista, I. S., and Gonzalez, A. L. C.: Effects of intense storms and substorms on the equatorial ionosphere/thermosphere system in the American sector from ground-based and satellite data, J. Geophys. Res., 102, 14 305-14312, 1997.

Tanaka, T.: Severe ionospheric disturbances caused by the sudden response of evening subequatorial ionospheres to geomagnetic storms. J. Geophys. Res., 86, 11 335-11349, 1981.

Tsugawa, T., Saito, A., Otsuka, Y., and Yamamoto, M.: Damping of large-scale traveling ionospheric disturbances detected with GPS networks during the geomagnetic storm, J. Geophys. Res., 108(A3), 1127, doi:10.1029/2002JA009433, 2003.
Tsugawa, T., Saito, A., and Otsuka, Y.: A statistical study of large-scale traveling ionospheric disturbances using the GPS network over Japan, J. Geophys. Res., 109, (A06302), doi:10.1029/2003JA01032, 2004.

Tsurutani, B., Mannucci, A., Iijima, B., Abdu, M. A., Sobral, J. H. A., Gonzalez, W., Guarnieri, F., Tsuda, T., Saito, A., Yumoto, K., Fejer, B., Fuller-Rowell, T. J., Kozyra, J., Foster, J. C., Coster, A., and Vasyliunas, V. M.: Global dayside ionospheric uplift and enhancement associated with interplanetary electric fields, J. Geophys. Res., 109, (A08302), doi:10.1029/2003JA010342, 2004.

Unnikrishnan, K., Balachandran Nair, R., and Venugopal, C.: A comparative study of nighttime enhancement of TEC at a low latitude station on storm and quiet nights including the local time, seasonal and solar activity dependence, Ann. Geophys., 20, 1843-1850, 2002,

SRef-ID: 1432-0576/ag/2002-20-1843.

Wilson, B. D.: Sub-daily northern hemisphere maps using the IGS GPS network, Radio Sci., 30, 639-644, 1995.

Yeh, K. C., Franke, S. J., Andreeva, E. S., and Kunitsyn, V. E.: An investigation of motions of the equatorial anomaly crest, Geophys. Res. Lett., 28, 4517-4520, 2001. 